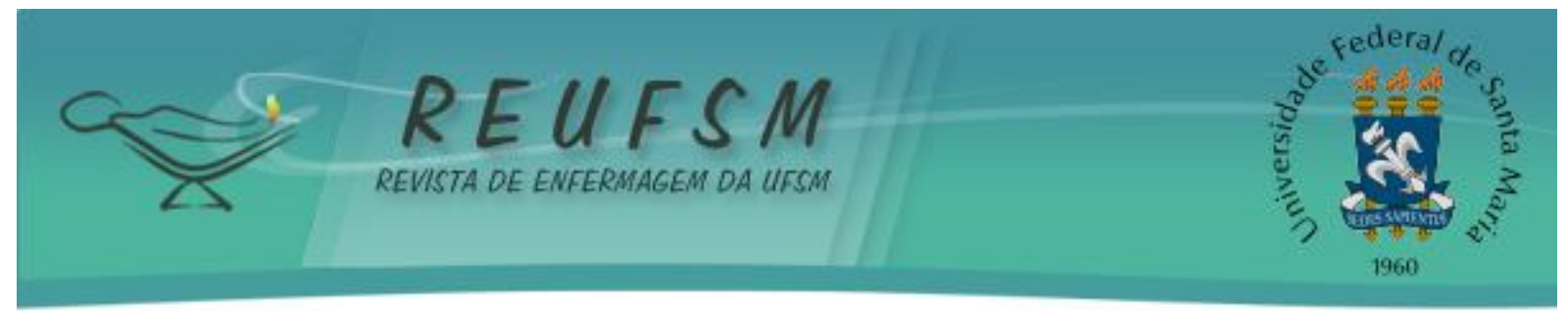

ARTIGO ORIGINAL

\title{
CONHECIMENTO DE AUXILIARES DE HIGIENIZAÇÃO SOBRE LIMPEZA E DESINFECÇÃO RELACIONADOS À INFECÇÃO HOSPITALAR
}

\author{
KNOWLEDGE OF HOUSEKEEPING CLEANERS ABOUT CLEANING AND DISINFECTION \\ RELATED TO HOSPITAL INFECTION
}

\section{CONOCIMIENTO DE AUXILIARES DE HIGIENIZACIÓN SOBRE LIMPIEZA Y DESINFECCIÓN RELACIONADOS A LA INFECCIÓN HOSPITALARIA}

\author{
Thamires de Araújo Paina ${ }^{1}$ \\ Jennifer Nathalie Rodrigues ${ }^{2}$ \\ Jessica Carolina Felippe ${ }^{3}$ \\ Paula Cristina Nogueira ${ }^{4}$ \\ Sonia Maria Alves de Paiva ${ }^{5}$
}

Doi: $10.5902 / 2179769212132$

RESUMO: Objetivo: identificar o conhecimento dos auxiliares de higienização sobre limpeza e desinfecção, relacionados à prevenção de Infecção Hospitalar. Método: pesquisa qualitativa, descritiva, realizada com 31 auxiliares de higienização de um hospital geral no sul de Minas Gerais. A coleta ocorreu entre setembro e outubro de 2013, por meio de entrevistas abertas. Os dados foram analisados segundo o referencial teórico de Minayo, pela análise de conteúdo e agrupados nas categorias: conhecimento sobre infecção hospitalar e realização dos procedimentos de limpeza e desinfecção. Resultados: as participantes demonstraram pouco conhecimento sobre infecção hospitalar e descreveram a realização dos procedimentos de limpeza e desinfecção, porém apresentaram falhas na realização destes procedimentos. Identificaram a importância de seu trabalho embora mencionassem insatisfação pela falta de reconhecimento e valorização profissional. Conclusão: os resultados evidenciaram a necessidade de capacitação no dia a dia de trabalho destes profissionais.

Descritores: Serviço hospitalar de limpeza; Infecção hospitalar; Capacitação profissional.

ABSTRACT: Aim: to identify the knowledge of housekeeping cleaners of cleaning and disinfection, related to prevention of hospital infection. Method: qualitative, descriptive research, carried out with 31 housekeeping cleaners of a general hospital in the south of Minas Gerais. The data collection occurred between September and October 2012, through open interviews. Data were analyzed according to the theoretical framework of Minayo, through content analysis, and were grouped into the categories: knowledge of hospital infection and performing disinfection and cleaning procedures. Results: participants showed little knowledge of hospital infection and described the cleaning and disinfection procedures, but there were flaws in performing these procedures. They identified the

\footnotetext{
${ }^{1}$ Enfermeira. Graduada pela Pontifícia Universidade Católica de Minas Gerais campus Poços de Caldas, Minas Gerais, Brasil. E-mail: thamires.paina@hotmail.com

${ }^{2}$ Enfermeira. Graduada pela Pontifícia Universidade Católica de Minas Gerais campus Poços de Caldas, Minas Gerais, Brasil. E-mail: jennifer.enf20@hotmail.com

${ }^{3}$ Enfermeira. Graduada pela Pontifícia Universidade Católica de Minas Gerais campus Poços de Caldas, Minas Gerais, Brasil. E-mail: jessik_2010enf@hotmail.com

${ }^{4}$ Enfermeira. Doutora em Ciência. Professor Doutor da Escola de Enfermagem da Universidade de São Paulo, Departamento de Enfermagem Médico-Cirúrgico, São Paulo - SP, Brasil. E-mail: pcnogueira@usp.br

${ }^{5}$ Enfermeira. Doutora em Enfermagem pela Escola de Enfermagem de Ribeirão Preto. Docente do Curso de Enfermagem da Pontifícia Universidade Católica de Minas Gerais campus Poços de Caldas, Minas Gerais, Brasil. E-mail: paiva@pucpcaldas.br
} 


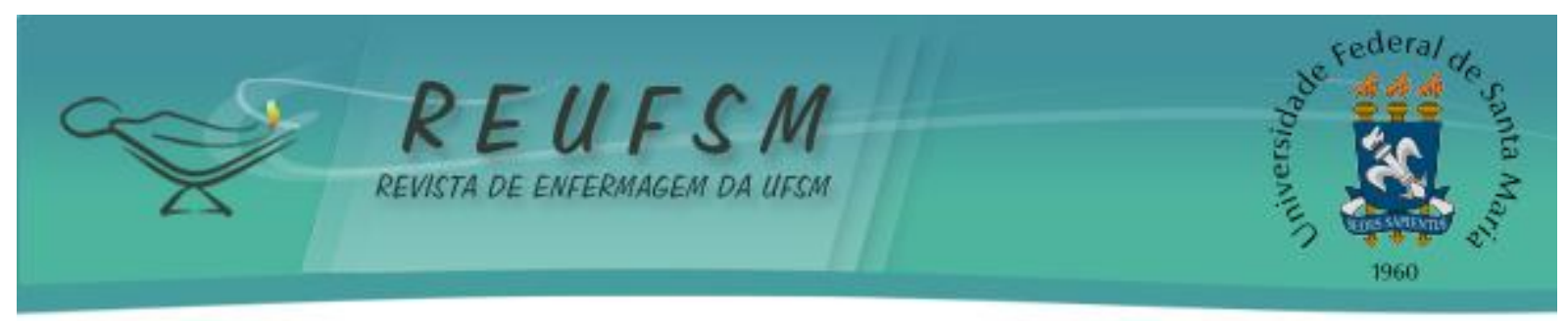

importance of their work, despite mentioning dissatisfaction by the lack of recognition and professional development. Conclusion: the results showed the need for training in day to day work of these professionals.

Descriptors: Housekeeping, Hospital; Cross infection; Professional training.

RESUMEN: Objetivo: identificar el conocimiento de los auxiliares de higienización sobre procedimientos de limpieza y desinfección, relacionados a la prevención de Infección Hospitalaria. Método: investigación qualitativa, descriptiva, realizada con 31 auxiliares de higienización de un hospital general, del Sur de Minas Gerais. La coleta ocurrió entre septiembre y octubre de 2013, a través de entrevistas abiertas. Se analizaron los datos según el marco teórico de Minayo, por el análisis del contenido y agrupados en las categorías: conocimiento sobre la infección hospitalaria y la realización de los procedimientos de limpieza y desinfección. Resultados: las participantes demostraron poco conocimiento sobre infección hospitalaria y describieron los procedimientos de limpieza y desinfección, todavía presentaron errores en la realización de estos. Identificaron la importancia de su trabajo aunque mencionasen la insatisfacción por la falta de reconocimiento y valoración profesional. Conclusión: los resultados evidenciaron la necesidad de capacitación del trabajo de estos profesionales.

Descriptores: Servicio de limpieza en hospital; Infección hospitalaria; Capacitación profesional.

\section{INTRODUÇÃO}

A limpeza hospitalar prepara o ambiente para suas atividades, previne a deterioração de superfícies, objetos e materiais ${ }^{1-2}$, remove as sujidades orgânicas e agentes patogênicos, com redução da incidência de colonização e infecção, ${ }^{3}$ com intuito de promover conforto e segurança aos pacientes. Os ambientes hospitalares contaminados são fatores de risco para infecções relacionadas aos serviços de saúde (IRAS), ${ }^{3}$ chamadas por infecção hospitalar $(\mathrm{IH})$.

Atualmente, o termo IRAS abrange não só a IH, mas também aquelas adquiridas em qualquer serviço de prestação de cuidados à saúde como ambulatórios, cuidados domiciliares, incluindo ainda as infecções adquiridas durante a jornada de trabalho pelos profissionais de saúde ao desenvolver algum procedimento de assistência ao paciente. ${ }^{4}$

A IH pode ser compreendida como o processo infeccioso adquirido no ambiente hospitalar relacionado à assistência à saúde. Segundo a Portaria MS $n^{\circ} 2616$ de 12/05/1998, a IH é definida como: "aquela adquirida após admissão do paciente e que se manifesta durante a internação ou após a alta, quando puder ser relacionada com a internação ou procedimentos hospitalares". 5:3

Cabe ao enfermeiro as medidas preventivas de $\mathrm{IH}$, pois é um integrante obrigatório do Serviço de Controle de Infecção Hospitalar $(\mathrm{SClH})$, conforme preconizado pela legislação vigente. ${ }^{5} \dot{E}$ função do enfermeiro educar e capacitar os profissionais que integram o serviço de saúde, principalmente os responsáveis pelos procedimentos de limpeza e desinfecção, com o intuito de barrar a cadeia de transmissão de microrganismos patógenos, diminuindo o risco de $\mathrm{IH}$ e melhorando a qualidade da assistência.

Os auxiliares de higienização, responsáveis pelos procedimentos de limpeza e desinfecção de superfícies, móveis, entre outros, desempenham papel importante na prevenção de IH. Assim, atentou-se para promover um estudo junto aos auxiliares de higienização de uma instituição hospitalar, que relacionasse seu conhecimento sobre IH com a prática diária, durante a realização dos procedimentos de limpeza e desinfecção, com foco na importância da prevenção das infecções. 


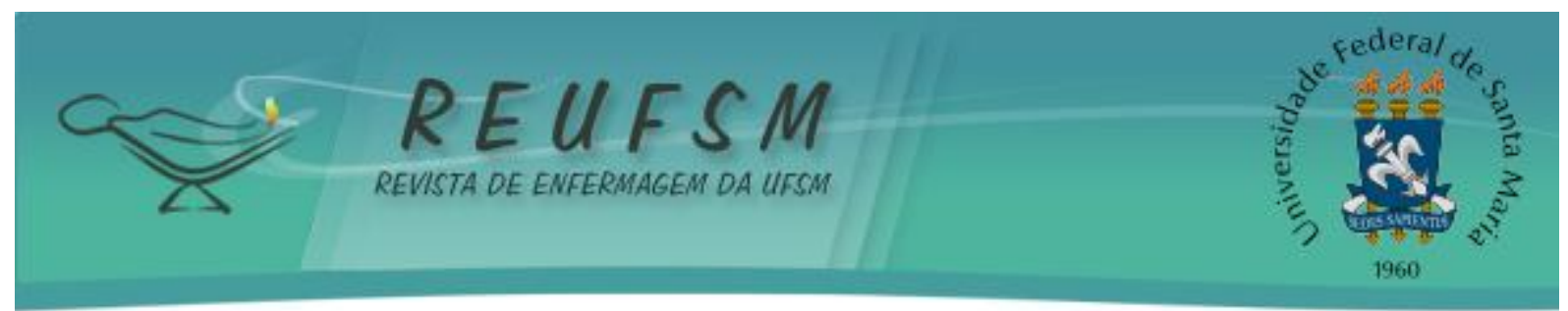

As questões que emergiram para o desenvolvimento da pesquisa foram: Qual o conhecimento dos auxiliares de higienização sobre $\mathrm{IH}$ e procedimentos de limpeza e desinfecção? Como são realizados estes procedimentos na prática diária? Quais são as capacitações oferecidas para realização de tais atividades?

Diante do exposto, objetivou-se identificar o conhecimento dos auxiliares de higienização sobre os procedimentos de limpeza e desinfecção, relacionados à prevenção de IH.

\section{MÉTODO}

Trata-se de um estudo descritivo, de abordagem qualitativa ${ }^{6}$, realizado em um hospital geral de grande porte, na cidade de Poços de Caldas, Minas Gerais, Brasil, no período de setembro a outubro de 2013.

A população foi composta por 42 profissionais, porém a amostra foi constituída por 31 destes, de acordo com os critérios de inclusão e exclusão. Foram definidos como critérios de inclusão atuar na equipe de higienização, no mínimo, há noventa dias e ser alfabetizado. Como critério de exclusão foi considerado estar ausente do campo de estudo em decorrência de férias e/ou afastamento legal.

A entrevista foi realizada individualmente, após orientações sobre a pesquisa e assinatura do Termo de Consentimento Livre e Esclarecido. Os discursos foram gravados e transcritos pelas pesquisadoras. Após, os dados foram analisados usando a análise de conteúdo. $^{6}$

A pesquisa foi aprovada pelo Comitê de Ética em Pesquisa da Pontifícia Universidade Católica de Minas Gerais (Parecer n 467.897 e Certificado de Apresentação para Apreciação Ética $\left.n^{\circ} 18356813.80000 .5137\right)$. Preservou-se o sigilo e anonimato dos sujeitos, que foram identificados por códigos (de E1 a E31), em cumprimento às recomendações da Resolução 466/12. ${ }^{7}$

\section{RESULTADOS E DISCUSSÃO}

Com base nos dados obtidos, caracterizou-se, na primeira etapa, o perfil sociodemográfico dos participantes. Dos 31 profissionais, todos eram do sexo feminino, a média de idade foi de 45 anos, variando entre 29 a 65 anos. Em outro estudo ${ }^{8}$, realizado com esta categoria profissional, em um hospital universitário no Paraná, sobre a capacitação para o trabalho entre trabalhadores de higiene e limpeza, obteve-se média de idade de 48,7 anos com uma população também predominantemente feminina $(96,9 \%)$. Isso ressalta a influência do gênero no trabalho de higiene e limpeza.

Quanto à experiência profissional, $10(32,26 \%)$ das entrevistadas ficaram entre as que tinham até um ano de trabalho na instituição, seguido das profissionais que tinham entre 5 a 10 anos, totalizando $9(29,03 \%)$, e das profissionais que tinham mais que 10 anos de trabalho em um total de $5(16,12 \%)$. Observa-se que 14 (45,16\%) apresentavam um tempo de experiência significativo na área da limpeza hospitalar.

Em relação à escolaridade das entrevistadas, 15 (48,39\%) tinham ensino fundamental incompleto, $7(22,58 \%)$ ensino fundamental completo, 6 (19,35\%) ensino médio incompleto, duas das entrevistadas cursaram ensino médio completo e uma cursava o ensino superior. Observa-se que a maioria $(70,9 \%)$ cursou o ensino fundamental.

Para a segunda etapa da pesquisa os dados foram analisados nas categorias descritas: 


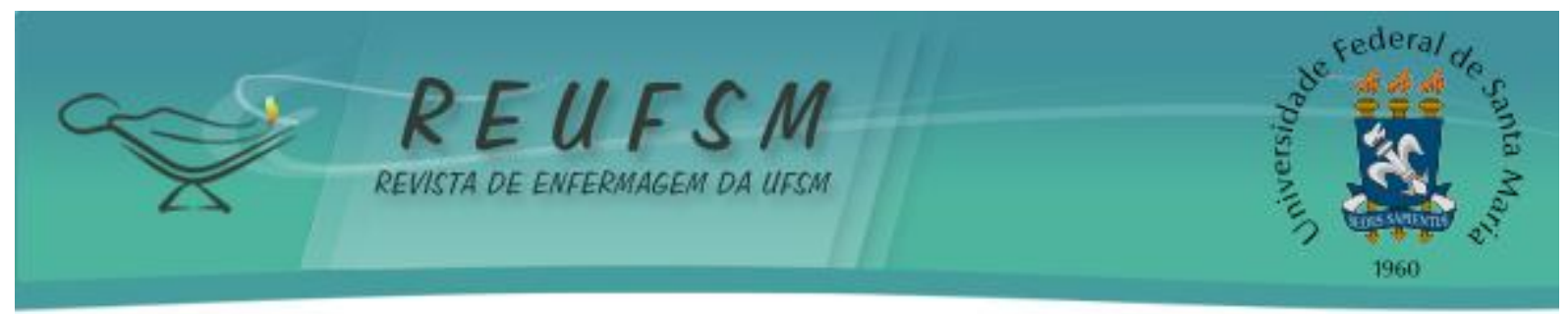

Conhecimento sobre Infecção Hospitalar

As entrevistadas conhecem as causas da $\mathrm{IH}$ e as identificaram nas falas. Ainda, relacionaram os procedimentos de limpeza e desinfecção e a lavagem das mãos com a prevenção da infecção, embora não apresentaram definições científicas sobre o tema.

É uma doença transmitida para o paciente que está em recuperação ou que fez alguma cirurgia. A causa da infecção hospitalar pode ser por falha de higienização. (E2)

É causada por bactérias, uma coisa mal higienizada e a falta de lavagem das mãos. (E10)

Importante os auxiliares de higienização reconhecerem a lavagem das mãos como medida preventiva para IH. Este ato é a atitude mais simples e não onerosa para prevenção das $\mathrm{IH}$, embora essa prática ainda seja negligenciada por muitos profissionais. ${ }^{9-10}$ Este tema tem sido foco prioritário de instituições de saúde e de programas como o da Aliança Mundial para a Segurança do Paciente, iniciativa da Organização Mundial da Saúde (OMS) juntamente com outros países para aumentar a adesão dos profissionais da saúde à higiene das mãos e garantir o controle de infecção. ${ }^{11-12}$

Nota-se pouco conhecimento quanto à origem da $\mathrm{IH}$, observado a partir das divergências nas falas das entrevistadas:

É uma bactéria e a gente tem que estar sempre limpando e cuidando para ela não aumentar. Se a gente não cuidar vai ter mais infecção ainda porque o paciente já vem com infecção. (E23)

É uma infecção que é pega dentro do hospital [...]. (E31)

Ainda assim, é possível perceber que as entrevistadas assimilam os processos de limpeza e desinfecção realizados na prática diária com a prevenção e controle da IH quando falam que "a gente tem que estar sempre limpando".

Estudos apontam que a falta de conhecimento sobre IH dos trabalhadores do serviço de limpeza hospitalar está associada à baixa escolaridade e a falta de conhecimento técnico-científico para atuar em ambiente insalubre, o que pode potencializar o risco ocupacional dos mesmos. ${ }^{13-14}$

\section{Realização dos procedimentos de limpeza e desinfecção}

A limpeza é o procedimento que tem a finalidade de remover a sujidade por meio de um processo mecânico, diminuindo assim a população microbiana do ambiente. Já a desinfecção é definida como processo físico ou químico capaz de destruir todos os microrganismos de forma vegetativa. ${ }^{2}$

Quando as auxiliares de limpeza foram indagadas sobre a diferença entre os procedimentos de limpeza e desinfecção, percebeu-se que embora as participantes não soubessem definir o que é limpeza e desinfecção, apresentaram algum conhecimento expresso por meio de ações realizadas nas situações diárias:

Na limpeza você só limpa, na desinfecção você mata os germes. (E3) 


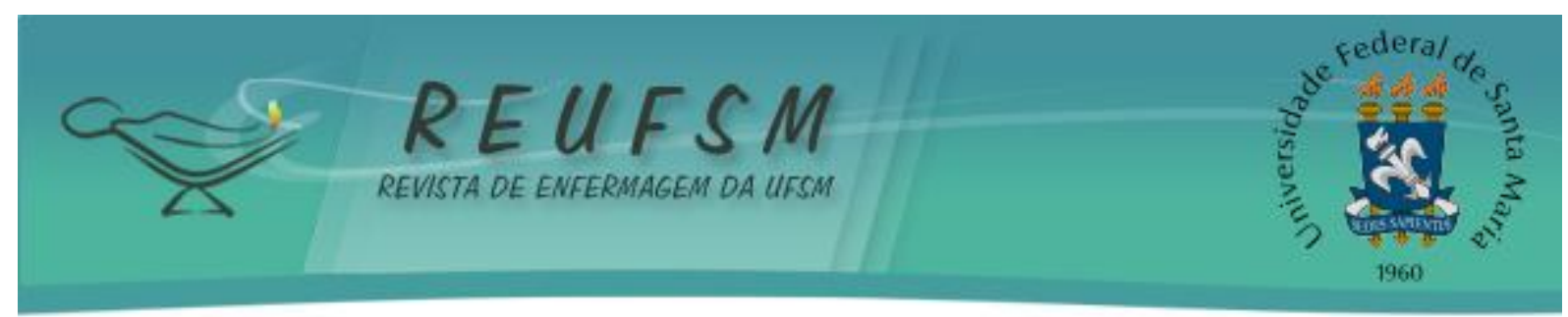

A limpeza é simples e a desinfecção é quando você usa um produto para matar as bactérias. (E4)

Para que a limpeza atinja seus objetivos, torna-se imprescindível a utilização de produtos saneantes, como sabões e detergentes. Em locais onde há presença de matéria orgânica torna-se necessária a utilização de desinfetantes. A desinfecção só atinge seus objetivos, quando utilizadas, primeiramente, as técnicas de limpeza. ${ }^{2}$

No questionamento sobre a técnica de desinfecção, constatou-se que os procedimentos padronizados não estavam sendo feitos de forma adequada, isto pode ocorrer devido à falta de conhecimento, deficiência em capacitações, e/ou por resistência dos profissionais.

Quando é uma coisa assim muito contaminada eu gosto de usar o hipoclorito. Eu acho que para as bactérias é melhor. (E19)

Na limpeza uso o hipoclorito, o biguanida e o sabão. A desinfecção é o mesmo procedimento, por exemplo, o lugar que têm sangue você joga o hipoclorito e deixa o sangue diluir e depois você passa água e sabão. Joga o hipoclorito primeiro porque aí você tem certeza que matou a bactéria. (E22)

Fica a cargo do $(\mathrm{SClH})$ da instituição a escolha pelos produtos saneantes e desinfetantes usados, desde que estejam de acordo com a legislação específica. ${ }^{2} \mathrm{Na}$ instituição pesquisada os desinfetantes padronizados eram o polihexametilenobiguanida (PHMB), o álcool a $70 \%$ e o cloro ativo inorgânico (hipoclorito a 1\%), que estão de acordo com as normas vigentes.

A gente lava o quarto todo com água e sabão, depois a gente vem com o biguanida no leito, janelas e chão. Passa o álcool a $70 \%$ na maçaneta, nas mesinhas de comida e naquelas bases de soro. (E27)

A limpeza hospitalar é realizada por meio de dois processos: concorrente e terminal. 0 processo concorrente é diário e tem finalidade de limpar e organizar o ambiente e estão incluídas as superfícies horizontais e instalações sanitárias. 0 terminal é feito em todos os componentes da unidade, incluindo todas as superfícies horizontais e verticais. É realizado na unidade do paciente após desocupação do local (alta hospitalar, transferências e óbitos) ou nas internações de longa duração. ${ }^{2}$

Quando foram questionadas sobre a diferença entre limpeza concorrente e terminal, não apresentaram dificuldade na conceituação:

A limpeza concorrente é quando tem paciente internado no quarto, a gente lava o banheiro, limpa os balcões, o quarto, as poltronas e o chão com varredura úmida [...] A terminal é diferente, pois desocupa todo o quarto, aí a gente limpa as paredes e todas as peças que têm. Os leitos são lavados, também os colchões e o chão, a gente esfrega com a máquina, depois enxágua tudo e passa cera. (E15)

As entrevistadas descreveram os procedimentos de limpeza e desinfecção hospitalar, porém, observam-se falhas na realização dos mesmos, quando detalharam como eles são feitos. 


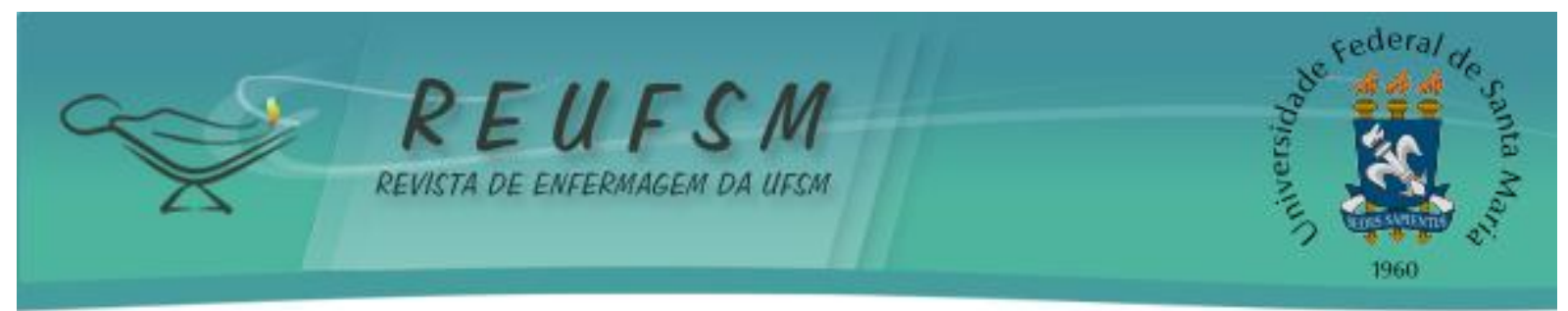

Quando foram indagadas sobre como realizavam as técnicas de limpeza e desinfecção apresentaram divergências nas afirmações, assim, conclui-se que os treinamentos não são sistemáticos e contínuos. Algumas das entrevistadas relataram realizar a desinfecção antes do procedimento de limpeza e retirada da matéria orgânica, fato este que não garante uma desinfecção de qualidade.

Funcionários do setor de limpeza hospitalar de um hospital universitário de Niterói$\mathrm{RJ}^{15}$, também apresentaram pouco entendimento sobre o procedimento de desinfecção hospitalar, $45,2 \%$ responderam que usa o desinfetante para deixar o cheiro bom, $2 \%$ não sabiam o porquê do uso do desinfetante e apenas $51 \%$ afirmaram que usam para destruir microrganismos.

Os estudos ${ }^{13-15}$ comprovam a necessidade de capacitações efetivas com os profissionais de limpeza hospitalar e cabe ao enfermeiro a realização destas atividades e o monitoramento dos resultados.

Quando as auxiliares de higienização foram questionadas sobre a freqüência de participações em capacitações, $14(45,16 \%)$ informaram que não sabiam ao certo, outras 8 $(25,80 \%)$ citaram que a frequência é mensal, $5(16,12 \%)$ disseram que acontece a cada três meses, e uma delas, descreveu que não ocorrem capacitações na instituição.

Os treinamentos são bastante frequentes. Não tem um tempo certo. (E15)

Como constatado, a maioria referiu que são realizadas capacitações, porém não souberam especificar a periodicidade. Diante das respostas pode-se inferir que estas não acontecem de forma sistemática. Fato esse que se evidencia, quando as participantes apresentaram divergências nas falas relacionadas ao procedimento de desinfecção, como já visto na discussão anterior.

A enfermagem exerce papel importante na atividade educativa das profissionais de higienização, pois é quem comanda as atividades de controle de IH e gerencia o serviço de apoio de limpeza. A legislação brasileira preconiza que os trabalhadores do serviço de limpeza hospitalar devem ser capacitados para o uso de Equipamento de Proteção Individual, prevenção do risco biológico e observação de princípios de higiene pessoal ${ }^{16}$ e a Lei 7498/86 que regulamenta o exercício profissional da Enfermagem traz no art. 11 suas atribuições: "prevenção e controle sistemático da infecção hospitalar e de doenças transmissíveis em geral, e a prevenção e controle sistemático de danos que possam ser causados à clientela durante a assistência à saúde". 17:2

Compete ao enfermeiro propiciar suporte organizacional e administrativo para atingir os objetivos estabelecidos, assegurar que a estrutura proverá e facilitará experiências de aprendizado para os trabalhadores, para que, no momento dispensado para a realização das atividades, eles estejam concentrados nelas. ${ }^{18}$

A avaliação das participantes sobre a importância de capacitações foi indicada pela maioria como oportunidade para relembrar técnicas e modos de usar os produtos, que com o tempo de serviço vão passando despercebidos. Entretanto, 4 (12,90\%) das entrevistadas, mencionaram que os treinamentos não acrescentam nenhum conhecimento novo.

É importante, mas ultimamente não tem falado nada de novo, seria bom se tivesse alguma novidade pra gente aprender coisas novas. (E4)

É necessário o envolvimento do trabalhador e a adesão à prevenção de $\mathrm{IH}$, com intuito de promover um elo de corresponsabilidade. A adesão significa consentimento, 


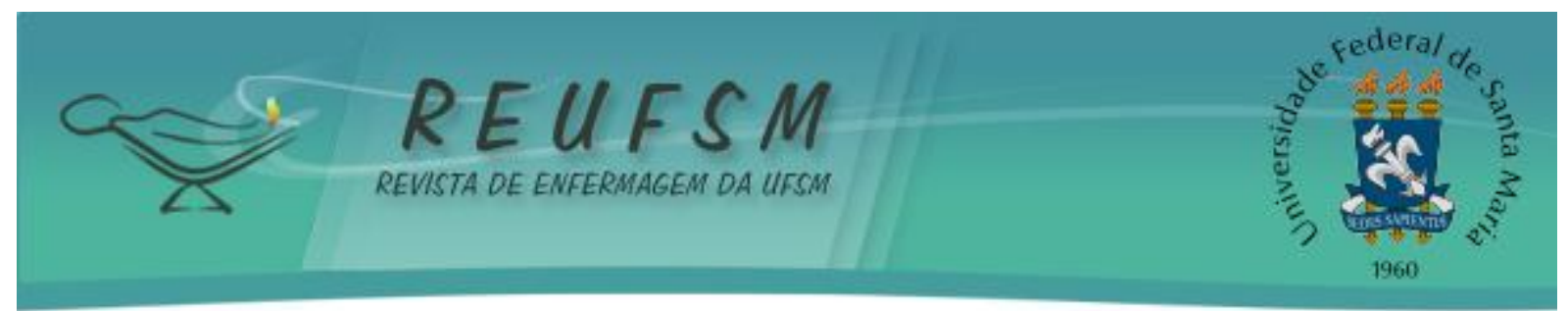

aprovação e participação de uma ideia. Manter atitude profissional adequada com estímulo e conhecimento técnico pode ser adquirido por meio de capacitações. ${ }^{19}$

As capacitações devem ser implementadas usando uma linguagem clara com termos acessíveis, presentes no cotidiano destes trabalhadores. O conteúdo programático deve abordar todas as técnicas que serão desempenhadas pelo colaborador de forma teórica e prática, para que a assimilação não seja prejudicada. ${ }^{2}$

$\mathrm{Na}$ instituição pesquisada, quem gerencia o serviço de limpeza é o profissional enfermeiro. Todavia, os dados demonstraram que há necessidade de um trabalho mais efetivo deste profissional, até porque, $10(32,26 \%)$ dos entrevistados eram iniciantes no serviço, com menos de um ano e necessitavam de capacitação específica para a atividade.

Outro aspecto a ser lembrado é a monitorização dos resultados obtidos e avaliação dos profissionais quanto às recomendações orientadas. Todo o trabalho de formação e orientação dos colaboradores deve promover a transformação das práticas profissionais e não se tornar apenas uma simples transmissão de conhecimentos e saberes técnicos, pois estes, por si sós, não garantem as transformações necessárias. ${ }^{20}$

Assim, além de considerar os aspectos técnicos, deve-se atentar para os conflitos vividos pelo trabalhador e deve haver preocupação se a informação transmitida está realmente sendo compreendida. ${ }^{15}$

Entre as falas sobre as questões norteadoras da pesquisa: conhecimento sobre $\mathrm{IH}$ e procedimentos de limpeza e desinfecção relacionados à prevenção de $\mathrm{IH}$, as auxiliares de higienização falaram do sentimento de desvalorização e inferioridade em relação aos outros profissionais que, muitas vezes, não reconhecem a sua importância e não as respeitam como integrantes da equipe. Notou-se que este sentimento é um dos conflitos vividos constantemente por estes trabalhadores.

[...] eu gosto de trabalhar aqui, apesar que a gente é muito discriminado. Tem pessoas aqui dentro que não são capazes de falar bom dia, entram no elevador juntinho com você e nem olham na sua cara, principalmente os médicos. Eles se esquecem de que a gente é igual, que não tem diferença nenhuma, porque se não tivesse a gente como eles iriam fazer o trabalho deles? E se não tivesse eles como é que os pacientes iriam sarar não é? Uma equipe, não é? (E29)

As profissionais citaram também que passam por situações de falta de cooperação entre a própria categoria.

Falta interesse dos outros, não consigo fazer o meu serviço direito porque tenho que corrigir o serviço dos outros. (E1)

Outro estudo ${ }^{21}$, realizado com esta população, que analisou o significado das cargas de trabalho para operacionais de limpeza de uma unidade de Emergência/Pronto Socorro em Londrina-PR, ressaltou nas falas destes profissionais os sentimentos de falta de reconhecimento no trabalho e relacionamento interpessoal ruim.

Embora o trabalho dos operacionais de limpeza pareça invisível para alguns, é uma atividade imprescindível à estrutura operacional do hospital. Trata-se de um serviço indispensável que garante segurança ao paciente, prevenção de acidentes e controle de infecções relacionadas á assistência. ${ }^{21}$

0 trabalho em equipe necessita, para sua efetivação, comunicação e integração entre os agentes envolvidos, no sentido de construírem consensos e acordos. ${ }^{22} \mathrm{~A}$ equipe 


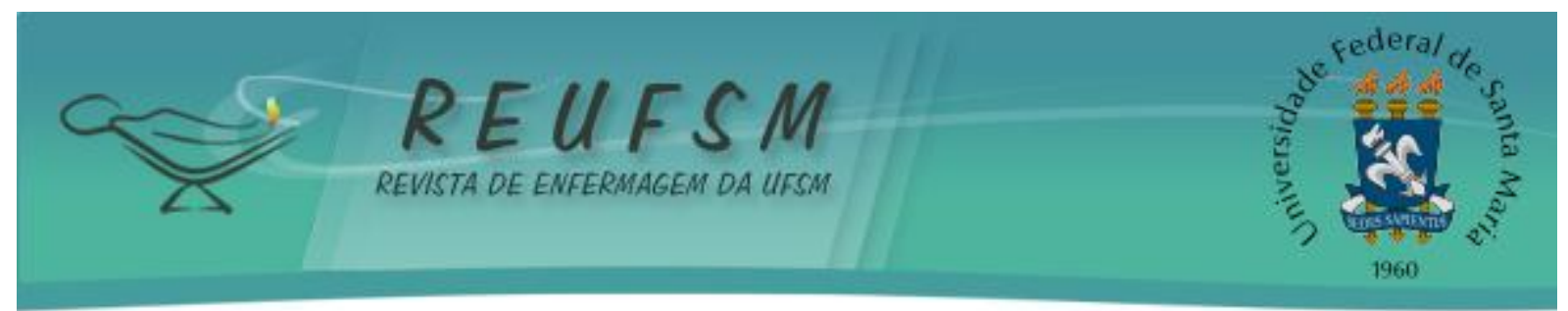

não existe apenas quando há vários profissionais numa mesma situação de trabalho e sim quando estes profissionais são realmente integrados.

O líder deve em primeiro lugar, buscar a valorização da sua equipe, por meio de atitudes que resgatem a autoestima dos liderados. Deve promover conhecimento do trabalho e desenvolvimento das capacidades, buscar motivação e comprometimento dos grupos de trabalhadores em direção aos objetivos comuns. ${ }^{18}$

\section{CONCLUSÃO}

Os resultados evidenciaram o predomínio do sexo feminino, idade média de 45 anos e baixo nível de escolaridade entre os pesquisados.

As auxiliares de higienização apresentaram conhecimento insuficiente sobre $\mathrm{IH}$ e em relação aos procedimentos relacionados à limpeza e desinfecção. Assim como, destacaram a falta de capacitação no serviço.

O serviço de limpeza é extremamente necessário e deve ser realizado de maneira adequada baseado em princípios e evidências científicas. Enfermarias onde o serviço de limpeza e desinfecção é feito de maneira inadequada propiciam a proliferação de microorganismos, o que aumenta a probabilidade de ocorrências de infecção hospitalar.

O baixo conhecimento e percepção dos auxiliares de higienização sobre IH apontam para a necessidade do planejamento de intervenções educativas. Os enfermeiros devem estar envolvidos diretamente nessa problemática, pois, freqüentemente lideram e chefiam a equipe de limpeza hospitalar.

Identificou-se a necessidade de educação continuada sistemática no serviço. É responsabilidade do enfermeiro educar e compartilhar informações aos seus colaboradores de forma teórica e prática. Também é seu papel trabalhar as relações interpessoais, valorizar a todos os elementos da equipe, incluindo os auxiliares de higienização. A gestão realizada pelo enfermeiro deve buscar melhores condições de trabalho com objetivo de alcançar a excelência dos cuidados prestados ao cliente.

Torna-se fundamental a continuação de novos estudos de investigação com essa população, muitas vezes esquecida, para que possam respaldar iniciativas que visem à prevenção da infecção hospitalar.

\section{REFERENCIAS}

1. Vecina Neto G, Malik AM. Gestão em saúde. Rio de Janeiro: Guanabara Koogan; 2011.

2. Brasil. Agência Nacional de Vigilância Sanitária. Segurança do paciente em serviços de saúde: limpeza e desinfecção de superfícies [Internet]. 2010 [acesso em 2012 set 1]. Disponível em: http://portal.anvisa.gov.br/wps/wcm/connect/4ec6a200474592fa9b32df3fbc4c6735/Manu $a l+L i m p e z a+e+D e s i n f e c c a o+W E B . p d f ? M O D=A J P E R E S$.

3. Ferreira AM, Andrade D, Rigotti MA, Ferreira MFF. Condition of cleanliness of surfaces close to patients in an intensive care unit. Rev Latinoam Enferm [Internet]. 2011 jun [acesso em 2014 dez 3];19(3):557-64. Disponível em: http://www.scielo.br/scielo.php?script=sci_arttext\&pid=S0104$11692011000300015 \&$ ing $=$ en .

4. Center for Disease Control and Prevention (CDC). Healthcare Associated Infections (HAI), 2011 [acesso em 2014 dez 10]. Disponível em: <http://www.cdc.gov/hai/index.html> . 


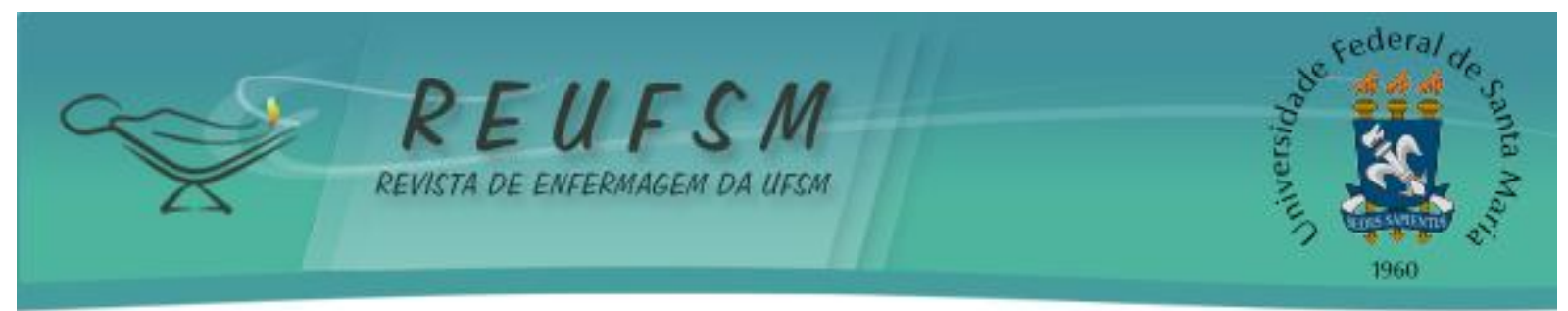

5. Brasil. Ministério da Saúde. Gabinete do Ministro. Portaria $n^{\circ} 2616 / M S / G M$, de 12 de maio de 1998. Regulamenta o Programa de Controle de Infecção Hospitalar (PCIH). Diário Oficial da União, Brasília; 1998 maio 13.

6. Minayo MC. O desafio do conhecimento: pesquisa qualitativa em saúde. São Paulo: Hucitec; 2010.

7. Brasil. Ministério da Saúde. Conselho Nacional de Saúde. Resolução CNS n 466, de 12 de dezembro de 2012. Aprova as diretrizes e normas regulamentadoras de pesquisas envolvendo seres humanos. Diário Oficial da União, Brasília; 2013 jun 13.

8. Silva LG, Haddad MCL, Domansky RC, Vituri DW. Capacidade para o trabalho entre trabalhadores de higiene e limpeza de um hospital universitário público. Rev Eletrônica Enferm [Internet]. 2010 [acesso em $2012 \mathrm{dez}$ 3];12(1):158-63. Disponível em: http://www.revistas.ufg.br/index.php/fen/article/view/5788/6602.

9. Helms B, Dorval S, Laurent PS, Winter M. Improving hand hygiene compliance: a multidisciplinary approach. Am J Infect Control. 2010;38(7):572-4.

10. Andrade D, Caliri MHL, Watanabe E. Una atencíon limpia es una atencíon segura. In: Cometto MC, Gómez PF, Dal Sasso GTM, Grajales RA, Cassiani SHB, Morales CF, editores. Enfermería y seguridade de los pacientes. Washington, D.C: Organizacíon Panamericana de la Salud; 2011. Cap. 15; p.211-24.

11. Erasmus V, Daha TJ, Brug H, Richardus JH, Behrendt MD, Vos MC, et al. Systematic review of studies on compliance with hand hygiene guidelines in hospital care. Infect Control Hosp Epidemiol. 2010 mar;31(3):283-94.

12. Bolon M. Hand hygiene. Infect Dis Clin North Am. 2011;25(1):21-43.

13. Cruz EDA, Pimenta FC, Hayashida M, Eidt M, Gir E. Staphylococcus aureus detection in the mouth of housekeepers. Rev Latinoam Enferm [Internet]. 2011 jan-fev [acesso em 2014 dez 11];19(1):90-6. Disponível em: http://www.scielo.br/pdf/rlae/v19n1/13.pdf.

14. Monteiro MI, Chillida MSP, Bargas EB. Educação continuada em um serviço terceirizado de limpeza de um hospital universitário. Rev Latinoam Enferm [Internet]. 2004 maio-jun [acesso em 2012 nov 6];12(13):541-8. Disponível em: http: / / www.scielo.br/scielo.php?script=sci_arttext\&pid=S0104-11692004000300013.

15. Valente GS, Falcão PM, Barbosa SQ, Rosa SG, Santos WA, Barbosa VQ. The nurse in health education to the employee cleaning in hospitals. Rev Pesqui Cuid Fundam [Internet] 2011 jan-mar [acesso em 2014 dez 11];3(1):1702-10. Disponível em: http://www.seer.unirio.br/index.php/cuidadofundamental/article/view/1227/pdf_367.

16. Brasil. Ministério do Trabalho e Emprego. Portaria $n^{\circ} 485$, de 11 de novembro de 2005. Aprova a Norma Regulamentadora $\mathrm{n}^{\circ} 32$ (Segurança e Saúde do Trabalho em Estabelecimentos de Saúde). Diário Oficial da União, Brasília; 2005. Seção 1.

17. Brasil. Lei $n^{\circ} 7498$, de 25 de junho de 1986. Dispõe sobre a regulamentação da enfermagem, e dá outras providências. Diário Oficial da União, Brasília; 1986 jun 26.

18. Bezerra FD, Andrade MFC, Vieira MJ, Andrade JS, Pimentel, D. Motivação da equipe e estratégias motivacionais adotadas pelo enfermeiro. Rev Bras Enferm [Internet]. 2010 jan/fev [acesso em 2013 jan 5];63(1):33-7. Disponível em: http://www.scielo.br/pdf/reben/v63n1/v63n1a06.pdf. 


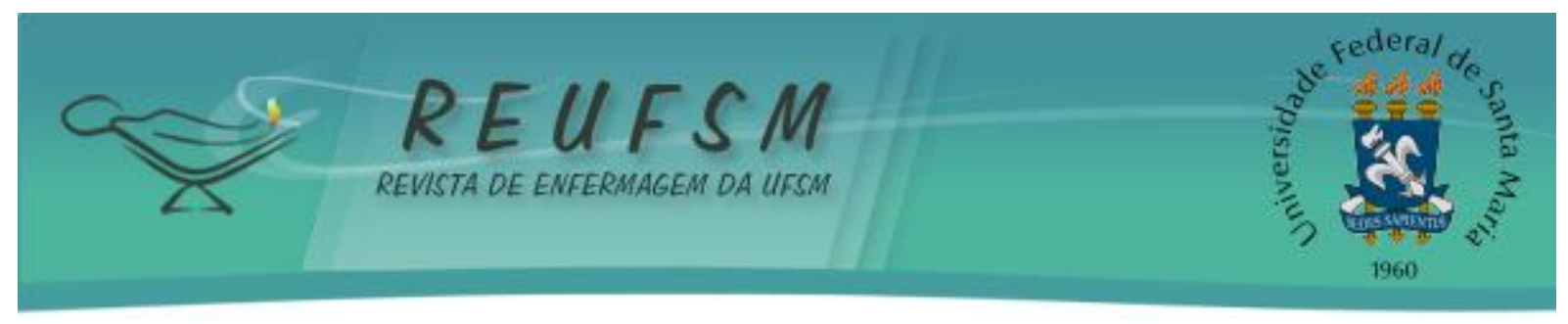

19. Silva EFF, Chrizostimo MM, Azevedo SL, Souza DF, Braga ALS, Lima JL. Um desafio para o controlador de infecção: falta de adesão da enfermagem às medidas de prevenção e controle. Enferm Glob [Internet]. 2013 jul [acesso em 2014 dez 1];12(31):316-56. Disponível em: http://scielo.isciii.es/pdf/eg/v12n31/pt_revision3.pdf.

20. Silva LAA, Leite MT, Hildebrandt LM, Pinno C. Educação permanente em saúde na ótica de membros das comissões de integração ensino-serviço. Rev Enferm UFSM [Internet]. 2013 maio/ago [acesso em 2013 out 25];3(2):296-306. Disponível em: http://cascavel.ufsm.br/revistas/ojs-2.2.2/index.php/reufsm/article/view/8476.

21. Martins JT, Ribeiro RP, Bobroff MCC, Marziale MHP, Robazzi MLCC, Mendes AC. Significado de cargas no trabalho sob a ótica de operacionais de limpeza. Acta Paul Enferm [Internet]. 2013 [acesso em 2014 out 25];26(1):63-70. Disponível em: http://www.scielo.br/pdf/ape/v26n1/11.pdf.

22. Bergamim MD, Prado C. Problematização do trabalho em equipe em enfermagem: relato de experiência. Rev Bras Enferm [Internet]. 2013 jan-fev [acesso em 2013 jun 3];66(1):134-7. Disponível em: http://www.scielo.br/pdf/reben/v66n1/v66n1a21.pdf.

Data de recebimento: $29 / 11 / 2014$

Data de aceite: 12/03/2015

Contato com autor responsável: Thamires de Araújo Paina

Endereço postal: Rua Corredeira, 235/apto 44 - Bairro Bosque da Saúde - CEP 04127-140 - São Paulo - SP, Brasil

E-mail: thamires.paina@hotmail.com 